\title{
Music Education, Aesthetics, and the Measure of Academic Achievement
}

\author{
Karl Madden, David Orenstein, Alexei Oulanov, Yelena Novitskaya, Ida Bazan, \\ Thomas Ostrowski, Min Hyung Ahn
}

Academic Department of the Library, Medgar Evers College, Brooklyn, New York, USA

Email: kmadden@mec.cuny.edu

Received 10 September 2014; revised 29 September 2014; accepted 10 October 2014

Copyright @ 2014 by authors and Scientific Research Publishing Inc.

This work is licensed under the Creative Commons Attribution International License (CC BY). http://creativecommons.org/licenses/by/4.0/

(c) (i) Open Access

\begin{abstract}
Grades and test scores are the traditional measurement of academic achievement. Quantitative improvements on standardized scores in Math/Science/Language are highly-coveted outcomes for meeting accreditation standards required for institutional program funding. Music and the Fine Arts, difficult to assess by traditional academic achievement measurement, and often devalued as so-called "luxury" subjects, struggle for necessary funding. Showing measureable collateral value to other academic subjects - such as math-in order to justify music program funding is dubious. To objectify the purpose of music education in terms of its influence on other subjects is to overlook aesthetic value. The scholarly literature recognizes an historical tendency to correlate music activities and aptitude to other subjects (and to intelligence in general), but quantitative causeeffect claims are not supported scientifically. Music participation from childhood helps build productive, well-socialized, excellent people, but to quantitatively trace the cause to music itself remains unproven. To recognize the benefits of music and the arts by aesthetic merit involves practical, holistic views of education not based on quantifiable test scoring.
\end{abstract}

\section{Keywords}

Music, Academic, Achievement, Aesthetics

\section{Introduction}

Academic achievement demonstrated by grades and test scores is the primary measure of student success, but the benefits of music elude empirical measurement. Quantifiable improvements on standardized test scoressuch as for math, science, and languages-are highly-coveted outcomes for accreditation and funding of institutional programs. Music, like other arts, is often considered a "luxury" subject. It has subjective, relatively un-

How to cite this paper: Madden, K., Orenstein, D., Oulanov, A., Novitskaya, Y., Bazan, I., Ostrowski, T., \& Ahn, M. H. (2014). Music Education, Aesthetics, and the Measure of Academic Achievement. Creative Education, 5, 1740-1744. 
quantifiable sets of achievement criteria, and therefore music programs often struggle for funding and survival. Efforts to justify music programs by showing measureable collateral value to more commonly-valued academic subjects is a tempting, practical endeavor, but to objectify the overall purpose of music education to its measurable influence on other subjects is questionable for both music and for the other subjects.

The scholarly literature recognizes an historical tendency to correlate music activities and aptitude to other subjects and to intelligence in general (Hodges, 2005: p. 23). However, correlative claims are idealistic and not clearly supported scientifically. Moreover, the recognition of the value of music on its own aesthetic merit is often overlooked. Music participation helps build well-rounded, well-socialized children, but there is little quantitative evidence of causal correlations between music and academic achievement (Schellenberg \& Weiss, 2013: p. 526). To recognize the benefits of music and the arts on their own aesthetic merits involves a practical, intuitive view of education and aesthetics not based on test scores.

Problems involved with scientifically demonstrating specific causal effects of music to academic achievement in other fields include, for example, the logistics involved in handling control groups (human research participants) in order to show cause/effect over prolonged periods of time. Furthermore, over time, research participants are naturally influenced by a vast array of complicated personal experiences, and to isolate music as specifically influential on development patterns depends on highly subjective methodology.

\section{Historical Context}

The ancient Greek philosopher Pythagoras demonstrated in the fifth century BCE that the physical properties of music involve mathematical relationships, such as the foundational harmonic ratio of 3:2. Current archeological research is revealing even much earlier perception of such ratios as related to aesthetic pursuits, such as the finding of clay tablets created around 2000 BCE that show tunings for stringed instruments (Southgate \& Roscigno, 2009: p. 5). Subsequent philosophers applied such knowledge to their understanding of the cosmos, thus arose the poetic term the music of the spheres, evoking the harmonic movement of the sun, moon, and planets. For the ancients, music, art, architecture, philosophy, poetry, and science were integral parts of an elegant, overarching art form, interconnected by the same spiritual, sensual, and mental aesthetic.

The important nineteenth-century public education administrator Horace Mann was among the first in more recent history to advocate for music inclusion in core curriculum. Although enthusiastically accepted that music studies are a marvelous contribution to a well-rounded education, proof of a cause-effect credit to music involvement for improvements in cognition and academic achievement was never clear. While cause-effect proof depends on a natural correlation, the correlation is no more than a condition (Vaughn, 2000: p. 154). In fact, it was only relatively recently that interdisciplinary social sciences research began to address causal correlation between music and other academic subjects.

\section{The Arts, Music, Testing, Sociology}

Participation in school music programs is well-known to correlate positively with all areas of student lives, including personal family life, community citizenship, academic achievement and student leadership (Catterall 1999: p. 3). Studies in impoverished areas of South America have demonstrated clear social and economic benefits because of improvements in attendance and grades correlating to student participation in music programs (Cuesta, 2011: p. 918). These clear correlations, though excellent, still do not scientifically show that music training is the actual cause. It could be a combination of general development as humans; it could be a general well-being at the core of the improvements; it could be that cognitive abilities lead students to music lessons, and/or that music lessons and the accompanying sense of accomplishment leads students to better cognitive engagement and subsequent abilities.

Attempts to substantiate the suggestion that simply listening to music (not learning it) improves cognitioneven intelligence-fall short of showing specific causal effect. The benefits of being in a good mood are practically all that can be inferred. Furthermore, in such studies, differences between short-term and long-term effects are not clearly delineated. Temporary improvements in cognitive functioning correlating to on mood and arousal enhancements experienced during sessions of listening to music are not shown to correlate with general, long-term academic achievement improvement (Schellenberg \& Weiss, 2013: p. 532).

Correlational studies often demonstrate improvement in non-music subjects by students enrolled in music courses (Hodges, 2005: p. 5). Did the music courses make the difference? It may be inferred, but has not been proven. In order to make a direct causal claim, one must demonstrate it across the whole of society, an endeavor 
that brings up more questions than answers. Is improvement a result of enhancement of cognitive skills because of music training, or, again, is it mostly motivation, self-discipline, and confidence enhanced by any activitymusic, drama, gymnastics, chess?

It is important to acknowledge that for all students of all socioeconomic levels there is correlational evidence linking academic success to involvement with music and the arts. This suggests that a major reason for high achievement is because families can afford the costs of involvement in music and arts organizations (Morrison 1994: p. 35).

\section{Language, Abstract Symbols, Mathematics}

There are correlations with music aptitude and language. Human infants are known to be acutely sensitive to prosodic patterns - the meaningful rise and fall of pitches and emphasis in sequences of spoken phrase (Patel, 2008: p. 4). Children who demonstrate phonological processing skills at early ages are also known to demonstrate musical abilities (Schellenberg, 2006: p. 121). These abilities may include reading skills, which engage abstract symbols of musical notation—as to written letters and words. In a similar way, students at ease with numbers and other abstract mathematical symbols also tend to show high aptitude with music.

The mathematical processing of performing and perceiving of music is simpler than may be assumed. Although pitch overtones and rhythmical meters are based on mathematical ratios and patterns, the perception of the identity of notes and the counting of beats usually involves only simple division, not algebra or calculus. One could say that music involves intuitive math skills.

There are many instances in the literature that draw correlations between good math test scores and involvement in music. For example, eighth and ninth grade students who had taken private music instruction for two or more years scored higher on math portions of certain standardized state-level tests. In the SAT test, positive correlations have been shown between music involvement and math scores (Vaughn, 2000: p. 151). Students who were active in music during middle and high school performed better in math than classmates who had not been active in music. This higher level of proficiency is shown to increase over time. The results were consistent across all socio-economic levels, but while correlations are clear, the main point is that it is difficult to make a clear cause-effect conclusion.

When considering cause-effect, one must again consider that motivation, conscientiousness, and supportive families are probably as important as the music lessons. Furthermore, schools with arts programs usually enjoy better funding — and therefore better programs in all disciplines (not just music and arts) — than poor schools. These socio-economic factors bleed into every aspect of correlative studies.

\section{Socioeconomics, Culture}

Music lessons and participation in school music groups cost money. Family structure and socioeconomics affect the affordability of instruments, lessons, transportation, and other costs associated with music programs. This is particularly meaningful in light of research that has shown that younger children across all social classes do not show variations in academic achievement according to whether or not they are involved with music, but that as they grow into adolescence, more involvement with music programs—associated with higher social class—does correlate with increasingly higher academic achievement levels. The role of parents is paramount, and social class differences influences the ability of working parents - often single parents dealing with multiple siblings— to assist their children with music (Southgate \& Roscigno, 2009: p. 10).

Racial and cultural differences also play a role, but these factors are less understood. Some of the statistical research shows that on average, Caucasian children are more involved with school music programs than Hispanic, African American, and Asian children (Southgate \& Roscigno, 2009: p. 13). In terms of extra-curricular, outside-school music lessons and programs, Asian adolescent students are most likely to be involved. Some socio-cultural traditions are at play. In Japanese culture, for example, parents are generally more inclined to involve students in extracurricular activities of all kinds. Though direct cause-effect correlations remain difficult to make, in general, students who are involved in any kind of extracurricular activity gain social confidence that positively influences all aspects of their lives.

\section{Music, Aesthetics, Neuroaesthetics}

Humans rely on language to describe the complex emotions aroused in response to music, and yet perhaps no 
area of the arts is more appropriate than music to the adage "words cannot explain". New research is going beyond the limitations of descriptive adjectives; it is measuring physiological responses in attempts to develop means of understanding aesthetic response.

Aesthetics, long associated with high culture and education, is now reaching into neuroscience, as researchers seek to explore biological contexts of aesthetic response in both humans and animals (Pannese, 2012: p. 599). Physiological responses to sound and music, and associations with sex, social activity, and food gathering, is not limited to humans. All animals_-including humans-may have developed evolutionary uses for music. The experiences of frogs singing and mating in a pond may be closely related to our hair-raising inspiration listening or performing the symphonies of Mozart, or the riffs of a heavy-metal rock song.

Previously thought of as two separate fields, sensory perception and discerning of taste (known as "aesthetics" in traditional science and humanities studies) both now comprise the field of "neuroaesthetics" (Brattico \& Pierce, 2013: p. 48). Research in this field supports the assertion that musical preference involves the integration of cognitive functions of music — music as a communicative tool—along with music as a means of physiological arousal.

Neuroaesthetics can indicate enhancements of the cognitive and emotional processes brought about in correlation to involvement with a variety of arts (and associated aesthetics). Students who maintain involvement in theatre arts (plays, drama clubs, acting lessons) not only show gains in reading proficiency, but also show increased self-esteem, motivation and empathy for others (Catterall, 1999: p. 2).

The study of aesthetics alone involves interdisciplinary interweaving of musicology, psychology, physiology, sociology, and history. The interplay of personality, habits of listening, social group membership, and the various related socio-cultural variables (clothes, activities), leads to the consideration of music as part of neuroscience and aesthetic domains (Brattico \& Jacobsen, 2009: p. 308). When one considers new technological advancements in neurology and aesthetic response, there promises a deepening understanding of the subject.

The intensity of dopamine release (the brain's reward chemical) triggered by experiencing sex and food (our primary evolutionary needs) is also influenced by complex aesthetic responses to beauty and positive memories. Communication, self-reflection, and physiological arousal related to listening to music, are primary contexts for the study music's relationship to human evolution (Schäfer \& Sedlmeier, 2010: p. 226).

The mantra "sex, drugs, and rock n roll" symbolizes an integrated triad of shared human experience reaching far beyond the teens-gone-wild stereotype. Narcotics artificially release dopamine (hence the addictive nature of narcotics abuse), and the combination of music, dopamine, and sex is a highly seductive feedback loop construct for the pleasure-seeking behavior at the core of human evolution. Meaning and perspective is gained through music - or through music's neurological effect on us - and this gaining of perspective provides aesthetic value-which, in the feedback loop, increases pleasure (Salimpoor, 2013: p. 64).

Musical phrases usually involve sequences of tension and release, anticipation and reward. It has long been asserted that emotional responses to music involve sequential processing in the brain based on anticipation, expectation and reward that correlates with musical phrases (Meyer, 2001: p. 344). This involves complex reasoning, leading to the desire and ability to feel the kinds of emotions-desire, satisfaction, pleasure, joy, fear-at the core of our being. This process of manufacturing circumstances - stories, music, aesthetics - that arouse emotional responses may be one of the main characteristics that make us uniquely human.

Participation in music and fine arts correlates and seems to enhance well-being, productivity, and improvements in academic performance, so music programs are intrinsic and necessary to a well-rounded education. To choose consider programs as expendable disregards the thrust of modern research. The research paradigm is shifting away from using empirical data alone to justify the value of music to education, but too often, school boards and administrators choose to ignore and therefore devalue music for its own sake. To prioritize science and language test scores is to misunderstand the integrated neuroaesthetic processes behind the overall social and academic benefits of music and arts education.

\section{Conclusion}

As the study of aesthetics broadens to include neuropsychology, the study of academic achievement is embracing the broadening research field. Overall, there is increasing intuitive acceptance of the correlative evidence that participation in music and the arts enhances the lives, desires, and abilities of students-leading to improved academic achievement—-despite the lack of specific cause-effect empirical data.

Increasing awareness of the interrelationships of the subjects involved-music, music response, aesthetics, 
neuroaesthetics, sociology, and others help to enhance the correlations to traditional subjects. If music and arts programs are supported, it will serve not only improvements in academic achievement across the curricula, but also the appreciation of music and the arts for their own aesthetic value, rich with qualities that defy quantitative analysis. As we become better able to recognize - and benefit from - the great, complex, and overarching aesthetic value of music and the arts, we should follow the sensible course- - to support and enhance music education above and beyond the simple purpose of academic achievement.

\section{References}

Brattico, E., \& Pearce, M. (2013). The Neuroaesthetics of Music. Psychology of Aesthetics, Creativity, and the Arts, 7, 4861. http://dx.doi.org/10.1037/a0031624

Brattico, E., \& Jacobsen, T. (2009). Subjective Appraisal of Music. Annals of the New York Academy of Sciences, 1169, 308317. http://dx.doi.org/10.1111/j.1749-6632.2009.04843.x

Catterall, J. S., Chapleau, R., \& Iwanaga, J. (1999). Involvement in the Arts and Human Development: General Involvement and Intensive Involvement in Music and Theatre Arts. In E. B. Fiske (Ed.), Champions of Change: The Impact of the Arts on Learning (pp. 1-18). Washington DC: Arts Education Partnership and President's Committee on the Arts and Humanities. http://artsedge.kennedy-center.org/champions/pdfs/ChampsReport.pdf

Cuesta, J. (2011). Music To My Ears: The (Many) Socioeconomic Benefits of Music Training Programmes. Applied Economics Letters, 18, 915-918. http://dx.doi.org/10.1080/13504851.2010.517187

Hodges, D. A. \& O’Connell, D. S. (2005).The Impact of Music Education on Academic Achievement. In M. Luehrsen (Ed.), Sounds of Learning: the Impact of Music Education (pp. 21-33). International Foundation for Music Research.

http://performingarts.uncg.edu/mri/research-areas/ files/solproject final.pdf

Meyer, L. B. (2001). Music and Emotion: Distinctions and Uncertainties. In P. N. Juslin and J. Sloboda (Eds.), Music and Emotion Series in Affective Science (pp. 341-360). New York: Oxford University Press.

Morrison, S. (1994). Music Students and Academic Growth. Music Educators Journal, 81, 33-37. http://dx.doi.org/10.2307/3398812

Pannese, A. (2012). A Gray Matter of Taste: Sound Perception, Music Cognition, and Baumgarten’s Aesthetics. Studies in History \& Philosophy of Biological \&Biomedical Sciences, 43, 594-601. http://dx.doi.org/10.1016/j.shpsc.2012.03.001

Patel, A. D. (2008). Music, Language, and the Brain. New York: Oxford University Press.

Salimpoor, V. N., \& Zatorre, R. J. (2013). Neural Interactions that Give Rise to Musical Pleasure. Psychology of Aesthetics, Creativity, and the Arts, 7, 62-75. http://dx.doi.org/10.1037/a0031819

Schäfer, T., \& Sedlmeier, P. (2010). What Makes Us Like Music? Determinants of Music Preference. Psychology of Aesthetics, Creativity, and the Arts, 4.4, 223-234. http://dx.doi.org/10.1037/a0018374

Schellenberg, E. G., \&Weiss, M. W. (2013). Music and Cognitive Abilities. In D. Deutsch (Ed.), The Psychology of Music (3rd Ed., pp. 499-550). Amsterdam: Elsevier. http://dx.doi.org/10.1016/B978-0-12-381460-9.00012-2

Schellenberg, E. G. (2006). Exposure to Music: The Truth about the Consequences. In G. McPherson (Ed.), The Child as Musician: A Handbook of Musical Development (pp. 111-134). Oxford, UK: Oxford University Press. http://dx.doi.org/10.1093/acprof:oso/9780198530329.003.0006

Southgate, D. E., \& Roscigno, V. J. (2009). The Impact of Music on Childhood and Adolescent Achievement. Social Science Quarterly, 90, 4-21. http://dx.doi.org/10.1111/j.1540-6237.2009.00598.x

Vaughn, K. (2000). Music and Mathematics: Modest Support for the Oft-Claimed Relationship. The Journal of Aesthetic Education, 34, 149. http://dx.doi.org/10.2307/3333641 
Scientific Research Publishing (SCIRP) is one of the largest Open Access journal publishers. It is currently publishing more than 200 open access, online, peer-reviewed journals covering a wide range of academic disciplines. SCIRP serves the worldwide academic communities and contributes to the progress and application of science with its publication.

Other selected journals from SCIRP are listed as below. Submit your manuscript to us via either submit@scirp.org or Online Submission Portal.
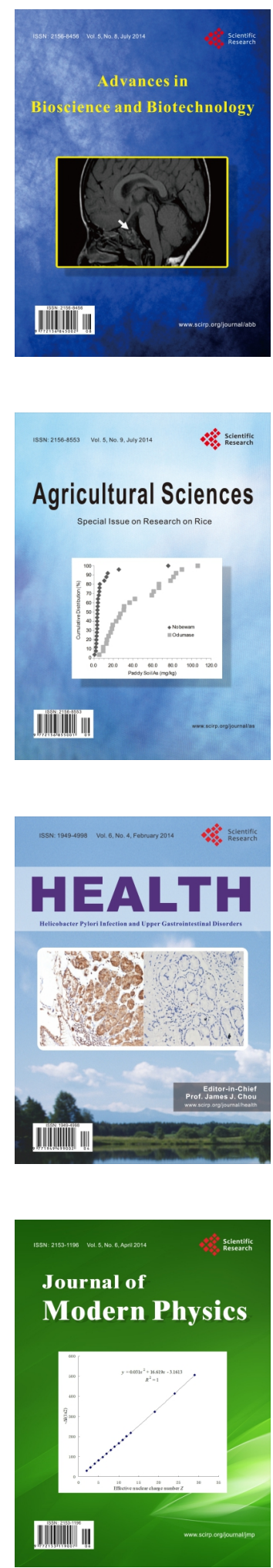
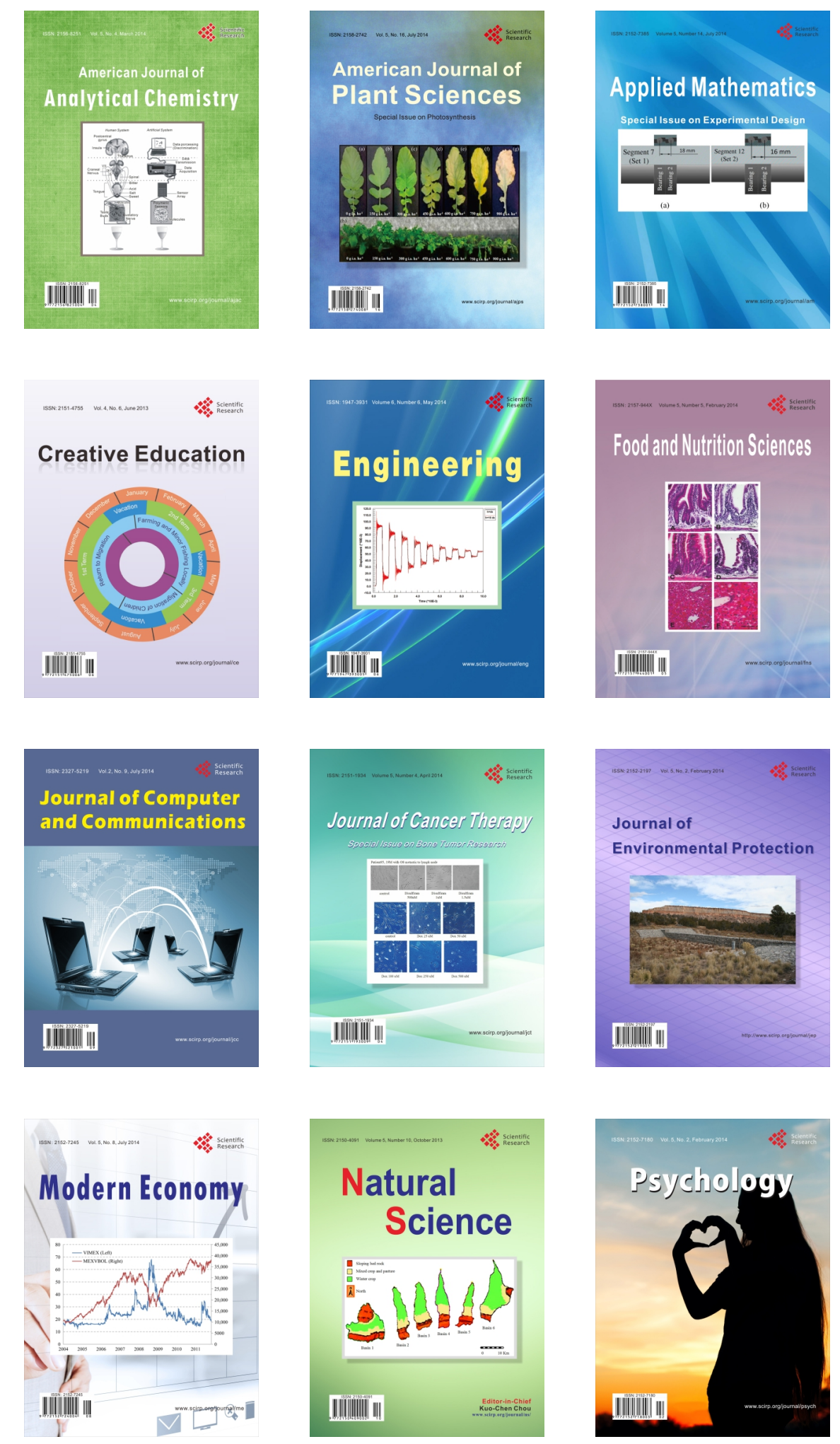